\title{
FREE TIME AND SOCIAL RELATIONSHIPS IN A GROUP OF STUDENTS FROM TWO HIGH SCHOOLS IN BOTOSANI COUNTY
}

\author{
Adriana Albu ${ }^{1}$, Mihaela Vlada ${ }^{2}$, Adina Nechita ${ }^{1}$, \& Florin Dima ${ }^{2}$ \\ ${ }^{1}$ Grigore T. Popa University of Medicine (Romania) \\ ${ }^{2}$ Vaslui Public Health Department (Romania)
}

\begin{abstract}
Introduction: it is necessary to assess the way students spend their free time in the final years of high school due to the poor results that have appeared recently in the baccalaureate exams. Methods: the study was carried out using a group of 202 students from the 11th and 12th grades from a National College (117 pupils) and a High School (85 pupils) from the city of Dorohoi, Botosani County. The young people filled in a questionnaire with questions about leisure activities and social relationships. The results were processed using Pearson's chi-squared test. Results and discussions: The time allocated daily for physical activity is mostly $15-30$ minutes $(23.76 \%)$ with significant differences between the two schools $(\mathrm{p}<0.05)$. The time spent watching TV is mostly $0.5-1$ hours (35.64\%) with insignificant differences between grades ( $>0.05)$. Most students $(44.05 \%)$ do not sit at the computer, the calculated differences being statistically insignificant $(\mathrm{p}>0.05)$. When looking at social relationships we take into account friends, where in the majority of cases (32.4\%) students have „one” true friend. This is a usual result because in this period of the adolescent's life the role the group of friends plays decreases, with significant differences between school years $(\mathrm{p}<0.05)$. In their free time, they go out into town, mostly $2-3$ evenings per week $(28.71 \%)$, but there are also $31.68 \%$ negative answers. Parents are less concerned about school activity ("never" answers $-34.15 \%$ ) with significant differences between grades $(\mathrm{p}<0.01)$. Parents are also less concerned with the way their children spend their free time ("never" answers $-34.65 \%$ ) with significant differences between school years $(\mathrm{p}<0.05)$. Conclusions: there is a series of situations that guide us towards a modest concern for the future, both from students and their parents.
\end{abstract}

Keywords: Free time, social relationships.

\section{Introduction}

In recent years, we have witnessed in Romania a drastic reduction in the percentage of students who finish high school. It is necessary to evaluate some factors that may explain the causes of this result. We focused on the elements represented by leisure activities and social relationships because they can be quite demanding.

Sports activities are a healthy way to spend your free time. There is an interesting result for students with anemia in Damanhur that should attract the attention of specialists. Those with anemia admit to exercising in a percentage of $44.2 \%$ and those without anemia in a proportion of $78.5 \%$ with significant differences (Naglaa \& Marwa, 2018). Daily physical activity contributes to the support of cardiac function, the development of motor and cognitive skills, to metabolic improvement (Haapala, 2013). Unfortunately, most young people do not pay attention to this way of spending their free time. Their favorite activities are watching TV shows and playing computer games. Such activities are also preferred by young women in Damanhour with and without anemia, but there are no significant differences, so it represents the same way of spending free time (Naglaa \& Marwa, 2018).

Adolescents in the Philippines recognize the constant watching of television programs as a main way of spending free time, while exercise is practiced "sometimes" or "often" (Yap, 2017).

Special attention should be paid to the time spent at the computer because currently, the literature describes the term "digital addiction" as highlighting the situations in which a person uses the computer intensely, uncontrolled, in a pathological way (Baciu, 2020). It also describes internet addiction present in people who use the internet in a pathological sense, being unable to use it constructively. Unfortunately, we reach a situation of social isolation, the appearance of stress reactions, and depressive states (Baciu, 2020). 
Social isolation can be associated with the orientation towards alcohol consumption, some drugs, and even with the emergence of ideas of suicide or self-aggression (Endo, Ando, Shimodera, Yamasaki, Usami, Okazaki, Sasaki, Richards, Hatch \& Nishida, 2017). Starting from these elements, special attention must be paid to body appearance and diets that are uncontrolled and performed only according to the recommendations obtained from the Internet. Serious eating problems can occur due to lack of control from family and low support from friends (Arseniev-Koehler, Lee, McCormick, Moreno, 2016; Haynos, Watts, Loth, Pearson \& Neumark-Stzainer, 2016).

In Romania, we pay special attention to food because we face a strong anchoring in the traditions of families. Sometimes there are deficient eating habits that will persist throughout life, which will affect the health of young people (Albu, Moraru \& Hodorcă, 2015). All these aspects must be in the attention of parents and preventive medical services. Specialized intervention is needed to address issues related to alcohol and drug use, unprotected sex, nutrition, and physical activity. Risky behaviors are becoming more common with age, so the role of preventive services is becoming increasingly important (Harris, Aalsma, Weitzman, Garcia-Huidobro, Wong, Hadland, Santelli, Park \& Ozer, 2017).

The objectives of the study: evaluation of the daily time allotted to physical activity; assessment of the daily time spent watching TV and especially on the computer; the presence of friends and the time spent with them outside the school program, which will allow for showing the presence of social isolation tendencies; parents' interest for school work and leisure taking into account the fact that adolescents want to become independent but still need guidance and support from the family.

\section{Method}

The study was carried out in Dorohoi, a small city in Botosani County. The studied group consists of 202 students from the 11th and 12th grades from a National College (high school - 117 young people) and a School Group (high school - 85 young people). 98 students from the 11th grade and 104 from the 12th grade were interviewed. Students completed a questionnaire with questions about how they spend their free time and their social relationships.

o Leisure was studied using three questions:

- How much sports or other physical activities do you practice per day (in minutes)?: under 15; 15-30; 30-45; 45-60; over 60 minutes.

- How many hours a day do you spend watching TV?: none; 0.5-1 hour; 2-3 hours; 4-5 hours.

- How many hours a day do you spend on the computer?: none; 0.5-1 hour; 2-3 hours; 4-5 hours.

o Social relationships were assessed using four questions:

- How many true friends do you have?: none; one; two, three, or more.

- In general, how many times per week do you go out with friends after school?: 0 times; 1 time, 2-3 times: 4-5 times; 6-7 times.

- Do parents (at least one of them) have time available to help you prepare your homework?: always; often; rarely; never.

- Do your parents have time to organize your free time?: always; often; rarely; never.

The processing of the results was done in between school years out of the desire to try to understand the disastrous results that have appeared lately in high school final exams.

The statistical interpretation was performed using Pearson's chi-squared test.

\section{Results}

The study focuses on two main directions represented by leisure time and social relationships.

When looking at free time activities, we will insist on physical exercise, watching television and using the computer. Sustained physical activity (over $60 \mathrm{~min}$.) is recognized by $19.30 \%$ of young people, the dominant response is $15-30 \mathrm{~min}$. $(23.76 \%)$ or $30-45 \mathrm{~min}(23.26 \%)$. Students in the 12 th grade do fewer sports, an easy situation to understand considering the time needed to prepare for the graduation exams, thusly the calculated differences are significant $\left(\mathrm{p}<0.05 ; f=4 ; \chi^{2}=10.213\right)$ (Table 1$)$.

Table 1. "How much sports or other physical activities do you practice per day?".

\begin{tabular}{|c|c|c|c|c|c|}
\hline & under 15 minutes & $15-30$ minutes & $30-45$ minutes & $45-60$ minutes & over 60 minutes \\
\hline 11th grade & 15 & 24 & 31 & 10 & 18 \\
\hline 12th grade & 30 & 24 & 16 & 13 & 21 \\
\hline Total & 45 & 48 & 47 & 23 & 39 \\
\hline$\%$ & 22.27 & 23.76 & 23.26 & 11.38 & 19.30 \\
\hline
\end{tabular}


Another leisure activity is watching television programs or playing computer games. Television programs are watched mainly 30 min-1 hour daily (35.64\%). There are also $32.67 \%$ young people who mark the "none" answer. There are $26.73 \%$ of teenagers who sit 2-3 hours a day in front of the TV screen and $4.95 \%$ who mark the "4-5 hours" answer. The calculated differences are statistically insignificant ( $\left.>0.05, f=3, \chi^{2}=3.076\right)$ an unexpected result in young people in the final years of high school who should be preoccupied with preparations for the graduation exams.

The situation is even more interesting in terms of time spent on the computer because $44.05 \%$ of students choose the "none" option. We must not overlook the $16.33 \%$ of students who mark the "4-5 hours" result which is difficult to understand especially for students in the 12th grade (Table 2).

Table 2. "How many hours per day do you spend watching TV/using the computer?".

\begin{tabular}{|c|c|c|c|c|}
\hline & None & $0.5-1$ hour & 2-3 hours & 4-5 hours \\
\hline & \multicolumn{4}{|c|}{ Television } \\
\hline 11 th grade & 32 & 40 & 22 & 4 \\
\hline 12 th grade & 34 & 32 & 32 & 6 \\
\hline Total & 66 & 72 & 54 & 10 \\
\hline \multirow[t]{2}{*}{$\%$} & 32.67 & 35.64 & 26.73 & 4.95 \\
\hline & \multicolumn{4}{|c|}{ Computer } \\
\hline 11 th grade & 40 & 22 & 19 & 17 \\
\hline 12 th grade & 49 & 22 & 17 & 16 \\
\hline Total & 89 & 44 & 36 & 33 \\
\hline$\%$ & 44.05 & 21.78 & 17.82 & 16.33 \\
\hline
\end{tabular}

The calculated differences are statistically insignificant $\left(\mathrm{p}>0.05 ; f=3 ; \chi^{2}=0.791\right)$ and draw attention to the young people in the final year who have time to sit at the computer, to socialize or play games.

In adolescents, social relationships diversify, being necessary to assess the existence of the group of friends but also the relationships with the parents. The group of friends is essential until the age of 14-15, after which its importance decreases, with restricted, selective friendships being preferred.

In the students in the studied group, the group of friends is still present in $28.21 \%$ of situations, but the calculated differences are statistically significant $\left(\mathrm{p}<0.05 ; f=3 ; \chi^{2}=8.33\right)$ which leads to the reduction of its role in young people in the final years of high school. The "none" answers in $10.89 \%$ of cases are worrying, which leads us to the situation of dangerous social isolation in this age group (Table 3).

Table 3. "How many true friends do you have?".

\begin{tabular}{|c|c|c|c|c|}
\hline & None & One & Two & Three or more \\
\hline 11th grade & 8 & 24 & 37 & 29 \\
\hline 12th grade & 14 & 39 & 23 & 28 \\
\hline Total & 22 & 63 & 60 & 57 \\
\hline$\%$ & 10.89 & 31.18 & 29.70 & 28.21 \\
\hline
\end{tabular}

The presence of the group of friends also means the existence of time spent with them outside of school. The result obtained is interesting because $31.68 \%$ of students mark the " 0 times" answer. Being a small town, there are not many possibilities to spend time somewhere with friends where teenagers will find it interesting (Table 4).

Table 4. "How many times per week do you go out with friends after school?".

\begin{tabular}{|c|c|c|c|c|c|}
\hline & 0 times & 1 time & $2-3$ times & $4-5$ times & $6-7$ times \\
\hline 11th grade & 35 & 24 & 24 & 8 & 7 \\
\hline 12th grade & 29 & 27 & 34 & 8 & 6 \\
\hline Total & 64 & 51 & 58 & 16 & 13 \\
\hline$\%$ & 31.68 & 25.24 & 28.71 & 7.92 & 6.43 \\
\hline
\end{tabular}

We can see that $7.92 \%$ of young people marked the " $4-5$ times" answer and $6.43 \%$ marked the "6-7 times" answer. The calculated differences are statistically insignificant ( $\left.\mathrm{p}>0.05 ; f=4 ; \chi^{2}=2.325\right)$ a result difficult to understand for young people in the final year of high school. These results require further study with the assessment of the parents' interest for the students' school activity.

In most cases $(34.15 \%)$ parents are not at all concerned about school activity. At the opposite pole are placed $13.36 \%$ of families in which this concern is permanent (Table 5). 
Table 5. "Do parents have time to help you with your homework? / Do parents have time to organize your free time?".

\begin{tabular}{|c|c|c|c|c|}
\hline & Always & Often & Rarely & Never \\
\cline { 2 - 5 } & \multicolumn{4}{|c|}{ Homework } \\
\hline 11th grade & 6 & 23 & 38 & 31 \\
\hline 12th grade & 21 & 18 & 67 & 38 \\
\hline Total & 27 & 41 & 32.17 & 34.15 \\
\hline$\%$ & 13.36 & 20.29 & 25 & 32 \\
\hline \multicolumn{5}{|c|}{ Free time } \\
\hline 11th grade & 7 & 34 & 27 & 38 \\
\hline 12th grade & 19 & 20 & 52 & 70 \\
\hline Total & 26 & 54 & 25.74 & 34.65 \\
\hline$\%$ & 12.87 & 26.73 & & \\
\hline
\end{tabular}

The calculated differences are statistically significant $\left(\mathrm{p}<0.01 ; f=3 ; \chi^{2}=11.375\right)$ and draw attention to the parents of pupils in the 12th grade who are more interested with preparing their homework.

Leisure activity is not supervised by $34.65 \%$ of parents; there are also $12.87 \%$ of families where there is permanent supervision. However, the significant differences calculated $\left(\mathrm{p}<0.05 ; f=3 ; \chi^{2}=9.125\right)$ are encouraging because they focus on the higher percentage of parents of students in the final high school year who are interested in this aspect.

\section{Discussion}

The focus is mainly on students in the 12th grade who will take the graduation exam. It is an important exam because it allows you to continue your studies at a college or a post-secondary school. Solving this problem requires in-depth study that leads to the minimization of free time.

Systematic physical activity is recommended for any age group. According to WHO recommendations, young people (5-17 years old) need at least 60 minutes of sustained activity per day, and adults (18-64 years old) need 150 minutes of moderate activity per day (WHO, 2017a; WHO, 2017b). Unfortunately for students in the studied group, such an answer appears only in $19.30 \%$ of situations, a result present in other studies carried out on adolescents from a high school in Iasi $(15.8 \%)$ who were not in the final year of high school (Albu, Onose, Negrea, Crăcană \& Hodorcă, 2015).

The modest time allotted for physical activity is recognized by most students, being present in $60.6 \%$ of young people in the USA (Miller, Sliwa, Brener, Park \& Merlo, 2016). Instead, these young people spend more than 3 hours per day watching television programs $(33.2 \%)$ or using the computer $(40.3 \%)$.

In Ghana, many young people have a $\mathrm{TV}$ in their room, which is turned on during their homework (27.6\%), have a personal computer/laptop (41.7\%) and even a gaming console (38.1\%) in their room, so they have all the conditions to spend too much time in front of the television or computer (Gaa, Apprey, Annan, Mogre \& Dzogbefia, 2019).

For students in the studied group, the result is interesting because there are many negative answers for both television programs (32.67\%) and computers (44.05\%). The study carried out on students from different high schools in Iasi highlights $22.78 \%$ negative answers for watching television programs and $11.81 \%$ for computer use (Albu, Hodorcă, Onose, Negrea \& Crăcană, 2016).

Adolescents in southeastern Iran respond negatively in $9.03 \%$ of situations for watching television programs and in 49.34\% of situations for computer use (Shahraki-Sanavi, Rakhshani, Ansari-Moghaddam \& Mohamad, 2017). At the same time, the daily physical activity that lasts 60 minutes is recognized by only $4.19 \%$ of girls. It is necessary to carry out in-depth studies related to students' habits of spending free time. These assessments are especially important for final high school years and students in large cities, but also in small cities where leisure activities are less numerous or tempting (Baciu, 2020).

Social relationships become essential for the evolution of young people. In the studied group there is an interesting situation represented by maintaining the group of friends ( 3 or more friends) after the age of $14-15$ years $(28.21 \%)$ which demonstrates a later maturation of students in the studied group. Unfortunately, there are many negative responses (I do not spend time outside of school with friends) which raises some worries related to the trend of isolation.

Parents still have an important role to play. They must closely monitor the student's school and leisure activities. We obtained an important result because the parents of the 12th-grade students are much more concerned with these aspects, however, permanent supervision is present in about $10 \%$ of families.

These are important issues because they can often be associated with inappropriate behavior. In England, lack of parental supervision (never/rarely) is associated with smoking (1.5\%), alcohol consumption (10.4\%), antisocial behaviors (18.5\%), behavioral problems (19.4\%) (Zilanawala, Sacker \& Kelly, 2017). 


\section{Conclusion}

Leisure activities must be closely supervised by parents as they can easily become tiring and disruptive for the sustained study required to complete high school. Sustained sports activity is not a concern of most students. There are many negative answers for watching television programs but also for computer activity, a special situation for high school students.

Social relationships are present in most cases but there is still a group of friends even in the $12^{\text {th }}$ grade which indicates a rather slow social evolution.

Parents of students who are in their final high school years are more interested in school and leisure activities of students because they are preoccupied with securing their future.

Such studies are important because they allow us to account for some factors that can be considered a risk in ensuring the future of young people.

\section{References}

Albu, A., Hodorcă, R. M., Onose, I., Negrea, M., \& Crăcană, I. (2016). The evaluation of the scholar fatigue phenomen and some causative factors in a group of teenagers from Iasi. Global Journal of Sociology: Curent Issues, 6(2), 44-49.

Albu, A., Moraru, C. E., \& Hodorcă, R. M. (2015). The evaluation of some eating habits at a group of teenagers studying at Dimitri Catemir highschool in Iasi. Procesia Social and Behavioral Sciences, 197, 1947-1951.

Albu, A., Onose I., Negrea M., Crăcană I., \& Hodorcă R. M. (2015). Correlation between physical development diagnostic and exercise in a group of teens from Garabet Ibrăileanu high school in Iasi. The European Proceedings of Social \& Behavioural Sciences, XI, 273-279.

Arseniev-Koehler, A., Lee, H., McCormick, T., \& Moreno, M. (2016). Proana:Pro-eting disorders socialization on Twitter. Journal of Adolescent Health, 58, 659-664.

Baciu, A. (2020). Digital addiction - an anthropological phenomenon of the preseent century. In Antropologia Mileniului III, București: Ed. Academiei Romane.

Baciu, A. (2020). Medical and social consequences of digital addiction. Medical Anthropology, The Publishing House of the Romanian Academy, 22(3), 141-147.

Endo, Ando, Shimodera, Yamasaki, Usami, Okazaki, Sasaki, Richards, Hatch, \& Nishida (2017). Preference for solitude, social isolation, suicidar ideation and self-harm in adolescents. Journal of Adolescent Health, 61, 187-191.

Gaa, P., Apprey, C., Annan, R., Mogre, V., \& Dzogbefia, V. P. (2019). The home and school environment, physical activity levels and adiposity indice of school-age children. International Journal of Public Health Science, 8,(1), 82-92.

Haapala, E. (2013). Cardiorespiratory firness and motos skills in relation to cognition and academic performance in children- a review. Journal of Human Kinetics, 36, 55-68.

Harris, S., Aalsma, M., Weitzman, E., Garcia-Huidobro, D., Wong, C., Hadland, S., Santelli, J., Park, J., \& Ozer, E. (2017). Research on clinical precentive services for adolescents and young adults:where are we and where do we need to go?. Journal of Adolescent Health, 60, 249-260.

Haynos, A., Watts, A., Loth, K., Pearson, C., \& Neumark-Stzainer, D. (2016). Factor predicting an escalation of restrictiv eating during adolescence. Journal of Adolescent Health, 59, 391-396.

Miller, G., Sliwa, S., Brener, N., Park, S., \& Merlo, C. (2016). School district policies and adolescents'soda consumption. Journal of Adolescent Health, 59, 17-23.

Naglaa, K. A. H., \& Marwa, M. A. O. (2018). Life style risk factors of iron deficiency anemia among adolescents'girls. International Journal of Nursing Didactics, 8(10), 18-28.

Shahraki-Sanavi, F., Rakhshani, F., Ansari-Moghaddam, A. \& Mohamad M. (2017). Association of physical activity and sedentary behavior with dietary behavior among mid-adolescent female students in southest of Iran. Medical Communication, bioscience biotechnology Research communication, 10(4), 739-745.

WHO, 2017a. Physical activity and adults. Recommended levels of physical activity for adults aged 18-64 years.

WHO, 2017b. Physical activity and young people. Recommended levels of physical activity for children aged 5-17 years.

Yap, R. A. (2017). Weight management: it's effect in the prevention of obesity related illness. International Journal of Physycal Education, Fitness and Sports, 6(4), 20-25.

Zilanawala, A., Sacker, A., \& Kelly, Y. (2017). Longitudinal latent cognitive profiles and psychosocial well-being in early adolescence. Journal of Adolescent Health, 61, 493-500. 